This item was submitted to Loughborough's Research Repository by the author.

Items in Figshare are protected by copyright, with all rights reserved, unless otherwise indicated.

\title{
Effects of horizontal whole-body vibration and standing posture on activity interference
}

PLEASE CITE THE PUBLISHED VERSION

PUBLISHER

(C) Taylor \& Francis

VERSION

AM (Accepted Manuscript)

LICENCE

CC BY-NC-ND 4.0

\section{REPOSITORY RECORD}

Baker, William D.R., and Neil J. Mansfield. 2019. "Effects of Horizontal Whole-body Vibration and Standing Posture on Activity Interference". figshare. https://hdl.handle.net/2134/6010. 
This item was submitted to Loughborough's Institutional Repository (https://dspace.lboro.ac.uk/) by the author and is made available under the following Creative Commons Licence conditions.

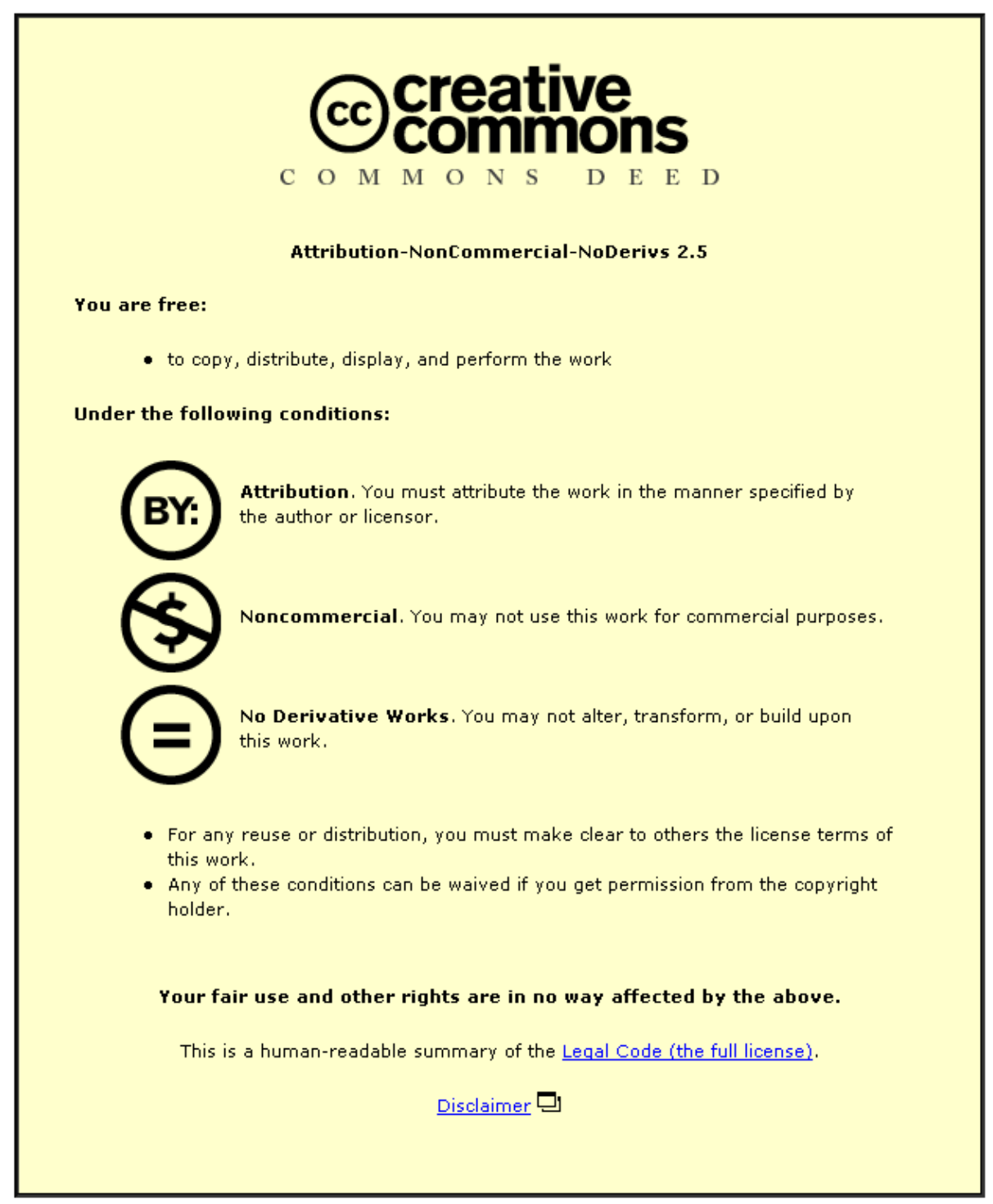

For the full text of this licence, please go to: http://creativecommons.org/licenses/by-nc-nd/2.5/ 


\section{Effects of Horizontal Whole-Body Vibration and Standing Posture on Activity Interference}

William D. R. Baker* and Neil J. Mansfield

Department of Human Sciences, Loughborough University, Loughborough, Leicestershire LE11 3TU, UK

* Corresponding Author.

Tel: +44 1509228485

Fax: +44 1509223940

Email Addresses: w.d.r.baker@lboro.ac.uk (W.D.R.Baker),

n.j.mansfield@lboro.ac.uk (N.J.Mansfield). 


\begin{abstract}
Standing people are exposed to whole-body vibration in many environments. This paper investigates the effects of horizontal whole-body vibration and standing posture on task performance. Sixteen participants were exposed to random vibration (up to 4Hz), whilst performing a timed pegboard task in two standing postures. Objective and subjective indicators of performance were used. Time taken to complete the task increased progressively with increases in vibration magnitude; the fore-and-aft posture generally showed greater performance decrements and postural interruptions $\left(>1.0 \mathrm{~ms}^{-2}\right.$ r.m.s.) than the lateral. For both postures, performance was better during yaxis vibration than during $\mathrm{x}$-axis vibration. Subjective ratings showed similar trends to time data. Impairments due to dual axis exposure were well predicted using r.s.s. summation calculations based on single axis components. These results indicate that best performance for those standing in moving environments will be achieved if individuals adopt a lateral posture with the most severe vibration in the $y$-axis.
\end{abstract}




\section{Statement of relevance}

People have a need to work during transportation either working for the transport provider or as a passenger. All modes of transport result in travellers being exposed to horizontal motion. This study demonstrates that task disturbance is affected by the orientation of the standing person to the vibration and therefore vehicle layouts can be optimised.

Keywords: Whole-body vibration; Standing posture; Performance; Manual Dexterity; Pegboard 


\section{Introduction}

Standing people are exposed to whole-body vibration (WBV) in many environments performing diverse tasks in a wide range of postures. For example, WBV is experienced for standing persons in public transport systems during peak travel when there is limited seat availability, for crew working in aircraft or trains serving refreshments, and for workers on ships or in ambulances. Due to the demands of a time-pressured culture there has been an increase in the proportion of people that utilise their travel time to perform various activities such as reading and writing as well as working on portable computers, mobile communications or other hand held devices (Mansfield, 2005). Reductions in size and weight, and the increased functionality of mobile communication technology have enabled increasingly complex tasks to be performed while standing but at increased susceptibility of activity interference due to motion.

WBV has been shown to impair performance of tasks requiring visual acuity and manual control (Lewis and Griffin, 1978). In terms of horizontal vibration Griffin and Hayward (1994) showed that a reduction in reading performance occurred for vibration magnitudes of $1.0 \mathrm{~ms}^{-2}$ r.m.s. and greater. More recently, Mansfield et al. (2007) considered the use of computer input devices under tri-axial vibration. The results identified no significant differences between 'zero' and 'low' $\left(0.508 \mathrm{~ms}^{-2}\right.$ r.s.s.) vibration magnitude conditions but differences were found between these and the 'high' $\left(0.878 \mathrm{~ms}^{-2}\right.$ r.s.s.) condition. The results indicated that low levels of vibration did not adversely affect performance when using these computer devices. However, other studies have shown that it is possible to compensate for disturbances due to 
WBV, maintaining task performance, but at the cost of increases in mental and physical workload (Conway et al., 2007; Newell and Mansfield, 2008).

Tracking tasks have largely been used to determine the effect of vibration direction on task performance. These types of tasks have, in essence, a performance bias that is dependant on the interaction between direction of tracking and the direction of vibration. It is important to assess the effects of vibration direction on performance of tasks that have no direction bias. Griffin and Hayward (1994) compared the effects of fore-and-aft (x-axis) and lateral (y-axis) horizontal wholebody vibration exposure on reading performance. The results showed that fore-and-aft vibrations, rather than lateral vibrations, produced greater reductions in reading speed. The magnitude of this effect however, appeared to be dependant on the presence of a seat backrest that could contribute to better transmissibility of fore-and-aft vibrations through the body as compared to lateral transmission (Mansfield and Maeda, 2007).

Previously there have been no studies that have considered the influence of feet position and posture on task performance for different directions of motion for standing persons. It could be hypothesized that posture could have direction dependant effects on task performance similar to the way in which tracking tasks are sensitive to specific directions of movement.

Griffin (1990) stated that in normal standing postures the effects of vertical vibration were similar to those in seated postures. There was no information, however, regarding the type of tasks or conditions on which these findings were based. Paddan and Griffin (1993) studied the effect of translational (fore-and-aft and 
lateral) vibration on the head motion of standing participants. These results were compared with those from a previous study that used seated participants with no backrest. It was found that the dynamics of a standing body might be considered to approximate those of a seated person with both postures showing similar measures for head motion. The similarity of measures between seated and standing participants enables extrapolations to be made regarding the effect of vibration on performance for standing postures.

According to Griffin (1990) the body is most unstable in the fore-and-aft direction whereas the lateral direction offers greater stability which may be improved by widening the separation of the feet; this statement implies that the legs and feet of the standing body are aligned within the y-axis (side-by-side). Nawayseh and Griffin (2006) found that the same displacement of the centre of pressure (COP) for both fore-and-aft and lateral motions produced a greater loss of balance during fore-and-aft exposure. It was determined that the base of support in the fore-and-aft direction was shorter than that in the lateral direction so a movement in the fore-and-aft direction would cause more instability than the same movement in the lateral direction. The effects of vibration on postural instability are not simply an issue of movement direction and the base of support of the individual must also be considered. The study acknowledged that there are situations where the base of support in the lateral direction is smaller than in the fore-and-aft direction, such as during walking, however there are no known studies that have considered these postures.

Previous research on standing vibration has aimed at determining the effects of posture on vibration transmissibility, particularly vertical vibration. Manual 
dexterity tests have only been used to study the after-effects of short and long duration vibration exposures (Banister and Smith, 1972 and Malchaire et al., 1998) with tracking tasks and reaction tests predominantly used to determine the effects of vibration on task performance (Lewis and Griffin, 1972) . This paper reports a study designed to investigate the effects of whole-body vibration on the performance of a discrete manual control task and to identify any postural effects based on two standing postures.

\section{Methods}

\subsection{Participants}

Sixteen healthy participants from Loughborough University (6 male and 10 female) aged 19-30 years (mean age: 23.5 years \pm 2.1 ) took part in the study. Participants were screened using a list of medical contra-indications that would have rendered them unfit for the experiment (British Standards Institute, 1973). Ethical approval was obtained from Loughborough University Ethical Advisory Committee and written consent was given by all participants.

\subsection{Vibration}

Fore-and-aft (x-axis), lateral (y-axis) and dual-axis (x-y-axes) horizontal vibration (with minimal vertical displacement) was presented using a 6 degrees-of-freedom multi-axis vibration simulator at the Environmental Ergonomics Laboratory, Loughborough University. Participants were required to stand on the simulator platform. For safety reasons, a harness was worn and secured above the simulator, a guard rail was mounted on three sides of the simulator platform. Participants were exposed to a control condition (no vibration) and nine different random vibration 
stimuli (Table 1) band-limited up to $4 \mathrm{~Hz}$. The greatest effect on performance in the $\mathrm{x}$ and y-axes has been found within the range 1-3Hz (Lewis and Griffin, 1978). Vibration magnitudes were selected based on the vibration experienced on trains. A study by Sundstrom (2006) used magnitudes between 0.4 and $0.8 \mathrm{~ms}^{-2}$ r.m.s. to represent low and high values of train vibration respectively and Suzuki (1998) found peak vibration magnitudes on trains in the range of $0.35-2.0 \mathrm{~ms}^{-2}$.

Table 1: Summary of horizontal vibration stimuli used in the experiment.

\begin{tabular}{|l|l|l|l|}
\hline \multirow{2}{*}{ Stimulus } & \multicolumn{2}{|l|}{ Vibration Magnitude (ms ${ }^{-2}$ r.m.s., unweighted) } \\
\cline { 2 - 4 } & X-Axis & Y-Axis & r.s.s. Axes \\
\hline 1 & 0.5 & - & 0.5 \\
\hline 2 & 1.0 & - & 1.0 \\
\hline 3 & 2.0 & - & 2.0 \\
\hline 4 & - & 0.5 & 0.5 \\
\hline 5 & - & 1.0 & 1.0 \\
\hline 6 & - & 2.0 & 2.0 \\
\hline 7 & 0.5 & 0.5 & 0.7 \\
\hline 8 & 1.0 & 1.0 & 1.4 \\
\hline 9 & 2.0 & 2.0 & 2.8 \\
\hline Control & - & - & - \\
\hline
\end{tabular}

Where: r.s.s. $=$ root sum of squares 


\subsection{Posture}

Two standing postures were selected for the study. The lateral posture required participants to place their feet side-by-side (Figure 1(a)), while the fore-and-aft posture required participants to place their dominant foot in-front of the other (Figure 1(b)). Distance between each foot was calculated as a percentage of stature, representing shoulder width (Pheasant and Haslegrave, 2006). This distance was measured from the distal portion of the second tarsal phalange in both the lateral and fore-and-aft postures. The lateral distance between the feet in the fore-and-aft posture was limited to the length of the foot of the participant. This ensured the base of support during both standing postures was equal. Foot wear was not provided for the participants however, running shoes were required to be worn by all participants. An upright posture with minimal hip flexion and unlocked knees was maintained throughout the duration of the vibration stimuli and coloured markers were placed on the platform to indicate the feet positioning for each posture. 


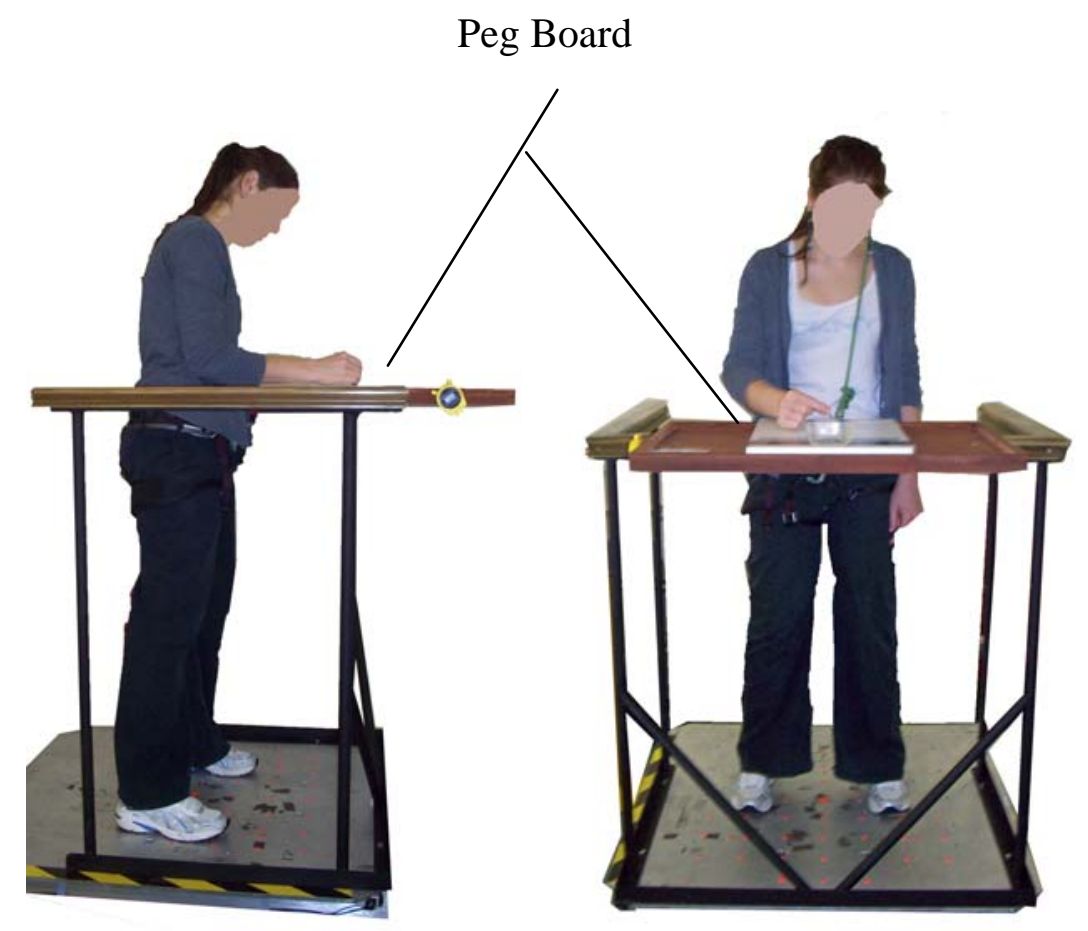

(a) Lateral posture

Timing switch

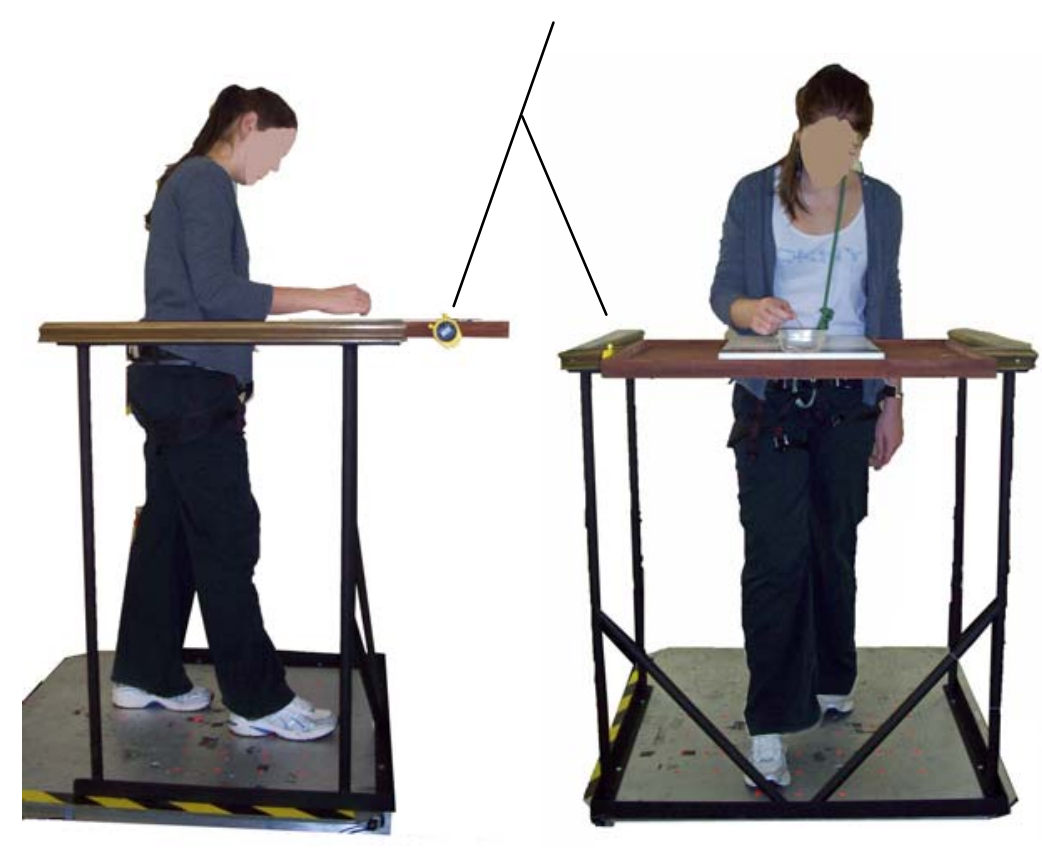

(b) Fore-and-aft posture

Figure 1: Subject demonstrating (a) the lateral standing posture and (b) the foreand-aft standing posture. 


\subsection{Task}

Using a Lafayette ${ }^{\circledR}$ Purdue Pegboard Model 32020, participants were required to select individual pegs from a container and place them into grooves on the pegboard, using only their dominant hand. The non-dominant hand remained by the side of the participants at all times, unless it was required for additional support in order to maintain stability. 25 pegs were placed for each test stimulus. The pegboard was designed to measure movements of the arms, hands and fingers in terms of speed and accuracy (Tiffin, 1948). A 'table-top' workstation was attached to the simulator platform at a standard height of $1000 \mathrm{~mm}$ above the platform surface. Mounted to the side of this work station was the timing device, positioned so that the 'Start/Stop' button was clearly visible to the participants but the display could not be seen. The pegboard was secured in a central position on top of the work station, a distance of $170 \mathrm{~mm}$ from the timer. Due to the movement of the platform and the workstation, a separate container (with dimensions of $60 \mathrm{~mm}(\mathrm{w}), 60 \mathrm{~mm}(\mathrm{~d})$ and $30 \mathrm{~mm}(\mathrm{~h})$ ) was required to store the pegs.

\subsection{Performance}

\section{Objective Measurement}

The performance of each participant was objectively measured using a timing device (Casio ${ }^{\circledR}$ stop-watch) to record the time taken to complete the task. Any motion induced interruptions that required the participant to physically brace themselves or adjust their stance in order to maintain balance were logged by the experimenter. 
Subjective Measurement

Participants were required to provide two subjective measures of task difficulty following the completion of each vibration condition. The first was a magnitude estimation rating of task difficulty. Participants received the following instructions, adapted from Stevens (1975):

'You will be presented with a series of vibration stimuli in irregular order. You are required to tell how difficult the tasks seem by assigning numbers to them. The first stimulus will be a static condition with no vibration. Call this stimulus 100, and then assign successive numbers in such a way that they reflect your subjective impression. There is no limit to the range of numbers that you may use. You may use whole numbers, decimals or fractions. Try to make each number match the level of difficulty as you perceive it.'

The second subjective measure required participants to rate the level of task difficulty on the following six-point semantic scale:

1. Not difficult

2. A little difficult

3. Fairly difficult

4. Difficult

5. Very difficult

6. Extremely difficult 
This semantic scale has previously been used with a magnitude estimation technique to determine measures of task difficulty and workload (Corbridge and Griffin, 1991). The use of both these techniques enables magnitude estimations of task difficulty to be calculated for each interval on the semantic scale.

\subsection{Procedure}

Once the required vibration magnitude was reached on the simulator, the participants were asked to 'Start' the timer and begin placing the individual pegs into position as quickly as possible. Once 25 pegs were completed the participants 'Stopped' the timer. Thus the total time comprised movement from the timer button, time to complete the 25 peg task and movement back to the timer button. The vibration stimulus was stopped at the completion of the task and the time taken to complete the task was recorded. At the end of each stimulus, participants were asked to provide the two subjective ratings of task difficulty. Each trial lasted between 60 and 90 seconds and the time between the trials was approximately the same. The short duration of the vibration exposures meant that time-dependent effects due to fatigue would not influence performance.

\subsection{Design}

Participants attended the laboratory for one testing session of approximately one hour, which commenced with the researcher taking stature and body mass measurements. Feet positioning was calculated and reference points were marked on the vibration platform. Each participant was allowed a familiarisation trial with no vibration to practice using the pegboard. This trial was used as a 'reference' and assigned a 
magnitude estimation of 100 for task difficulty. The order in which the vibration stimuli were presented was randomised using a counter-balanced Latin-Square.

\subsection{Data Analysis}

A non-parametric Wilcoxon matched-pairs signed ranks test was carried out on all the data to determine whether vibration magnitude, vibration direction and standing posture had a significant effect on task performance and task difficulty. The twotailed test was used and statistical significance was accepted at the $5 \%$ level $(p<$ $0.05)$.

\section{Results}

\subsection{Objective Task Performance}

Performance decrements were based on the mean time taken to complete the task at each magnitude, an increase in time illustrating a reduction in performance.

For $\mathrm{x}$-axis vibration, the mean time to complete the task (for both postures) increased significantly $(p<0.05)$ with vibration magnitude between $0.0 \mathrm{~ms}^{-2}$ r.m.s. and $2.0 \mathrm{~ms}^{-2}$ r.m.s. (Figure 2(a)). At each magnitude the highest mean times were found to occur in the fore-and-aft posture, however this effect was not significant, possibly due to the small sample size used in the study. 
(a)

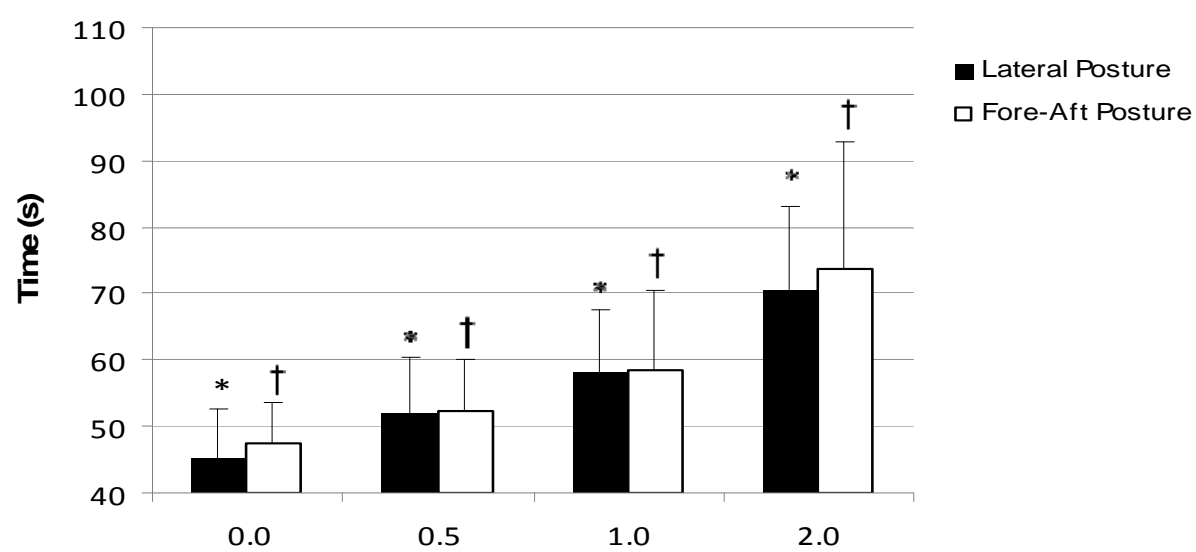

(b)

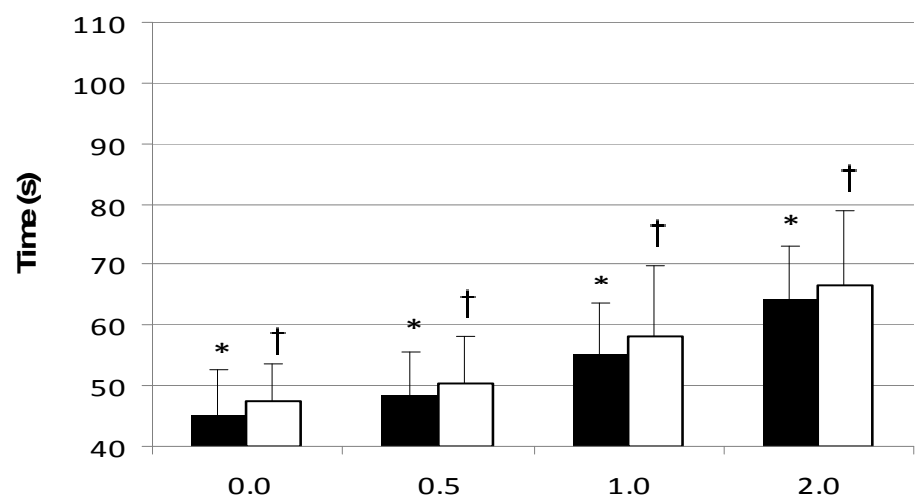

- Lateral Posture

$\square$ Fore-Aft Posture

(c)

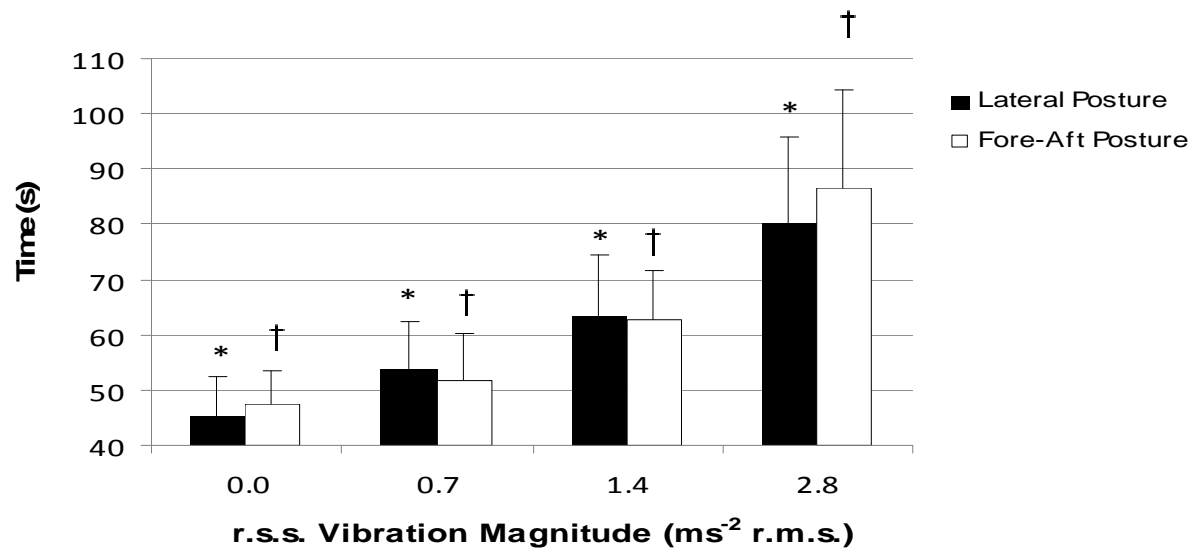

Where: * = significant difference $(p<0.05)$ between vibration magnitudes for the lateral posture

$\dagger=$ significant difference $(p<0.05)$ between vibration magnitudes for the fore-and-aft posture

Figure 2: Comparison between fore-and-aft and lateral standing postures illustrating the mean time taken to complete the pegboard task during exposure to vibration in the (a) $x$-axis, (b) $y$-axis and (c) $x$-y-axes. 
For y-axis vibration, a significant $(p<0.05)$ increase was found in the mean times to complete the task with vibration magnitude between $0.0 \mathrm{~ms}^{-2}$ r.m.s. and $2.0 \mathrm{~ms}^{-2}$ r.m.s., for both lateral and fore-and-aft postures (Figure 2(b)). The fore-andaft posture showed higher mean times compared to the lateral posture at each vibration magnitude, however these postural effects were not significant. At the highest vibration magnitude $\left(2.0 \mathrm{~ms}^{-2}\right.$ r.m.s.) the mean times to complete the task were significantly $(p<0.05)$ shorter during $\mathrm{y}$-axis vibration exposure as opposed to $\mathrm{x}$-axis vibration exposure, for both postures.

For dual axis vibration, the mean times to complete the task in both postures increased significantly $(p<0.05)$ with an increase in vibration magnitude (Figure 2(c)). The effect of different postures showed some variation. The fore-and-aft posture caused lower mean times than the lateral posture at magnitudes $0.7 \mathrm{~ms}^{-2}$ r.m.s. and $1.4 \mathrm{~ms}^{-2}$ r.m.s. however the fore-and-aft posture showed significantly $(p<0.05)$ higher mean times at magnitude $2.8 \mathrm{~ms}^{-2}$ r.m.s. Compared to single axis vibration, dual axis vibration produced significantly $(p<0.05)$ higher times to complete the task. This would be expected as the resultant r.s.s. vibration magnitude was higher for dual axis vibration.

\subsection{Subjective Measures of Task Difficulty}

During $\mathrm{x}$-axis vibration exposure, the magnitude estimations of task difficulty increased significantly $(p<0.05$ ) with an increase in vibration magnitude for both lateral and fore-and-aft postures (Figure 3(a)). No significant differences were found between the two postures, however the fore-and-aft posture showed slightly higher mean levels of task difficulty than the lateral posture. 
For y-axis vibration (Figure 3(b)), task difficulty also increased significantly $(p<0.05)$ with increases in vibration magnitude. At vibration magnitudes $0.5,1.0$ and $2.0 \mathrm{~ms}^{-2}$ r.m.s. the fore-and-aft posture caused significantly $(p<0.05)$ higher mean estimations of task difficulty than the lateral posture. At these vibration magnitudes, task difficulty estimations obtained during y-axis vibration exposure were significantly $(p<0.05)$ lower than those obtained during $\mathrm{x}$-axis vibration exposure. The lower task difficulty estimations indicate that y-axis vibration caused less workload to be placed on the participants than x-axis vibration.

For both lateral and fore-and-aft postures, estimations of task difficulty increased significantly $(p<0.05)$ with increases in vibration magnitude. No significant differences were found between the two postures. Dual axis vibration resulted in significantly ( $p<0.05$ ) higher estimations of task difficulty compared to the single axis responses.

Similar patterns were observed for the semantic scale data, when coded according to category rank. Task difficulty, based on semantic ratings, increased significantly $(p<0.05$ ) with increases in vibration magnitude, during exposure to the $\mathrm{x}$ - and $\mathrm{y}$-axes individually and during dual axis vibration. 
(a)

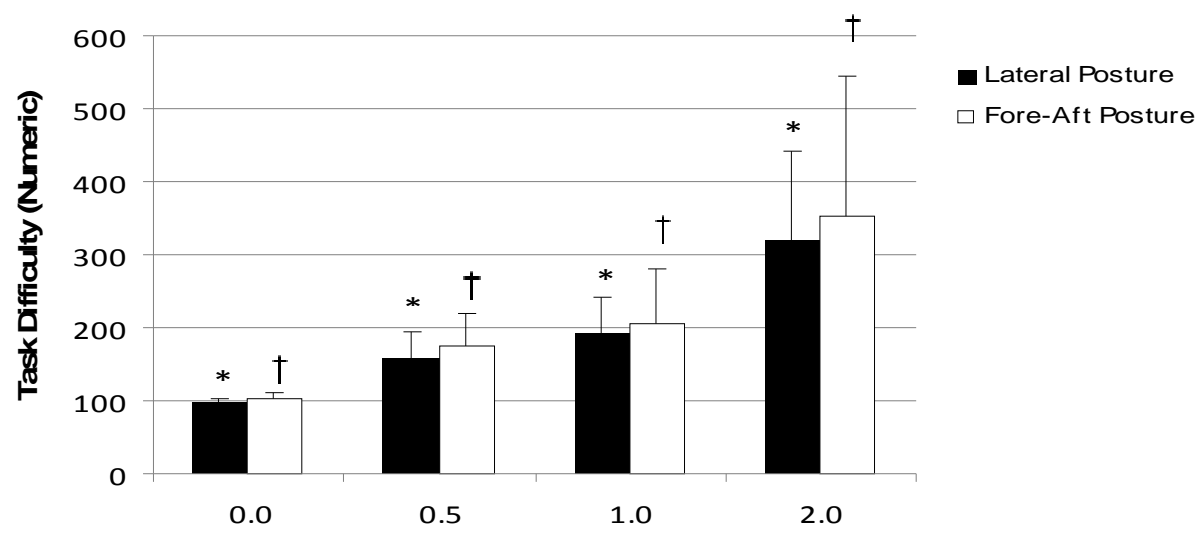

(b)

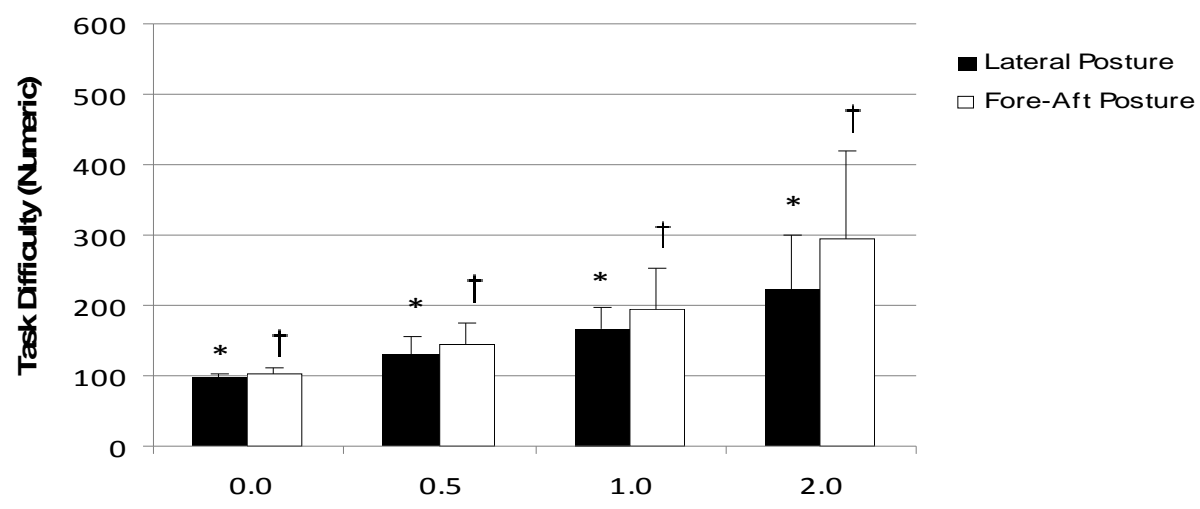

(c)

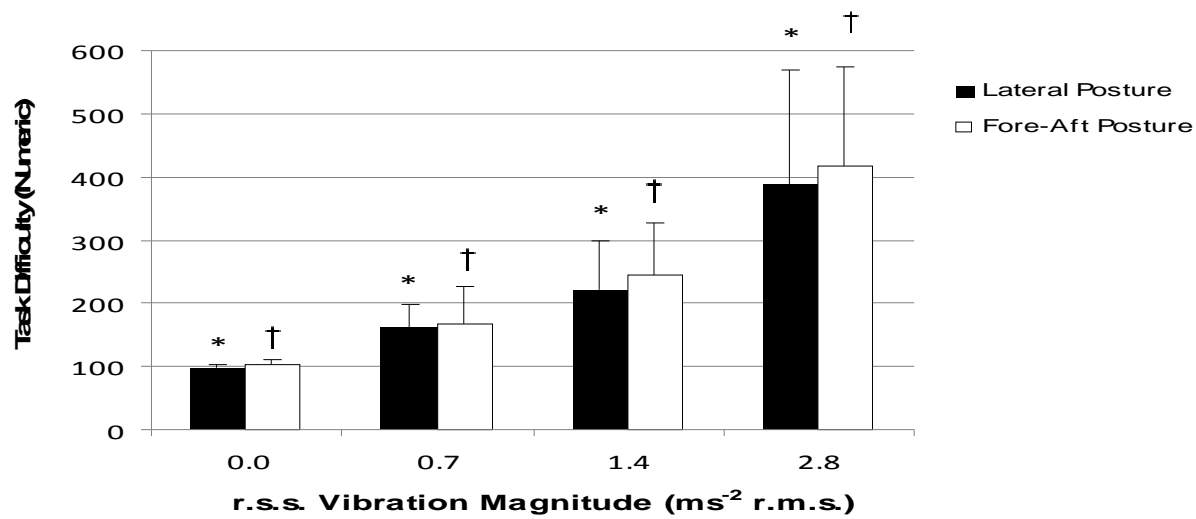

Where: $*$ significant difference $(p<0.05)$ between vibration magnitudes for the lateral posture

$\dagger=$ significant difference $(p<0.05)$ between vibration magnitudes for the fore-and-aft posture

Figure 3: Comparison between fore-and-aft and lateral standing postures illustrating the mean magnitude estimations of task difficulty during exposure to vibration in the (a) $x$-axis, (b) $y$-axis and (c) $x$-y-axes. 


\subsection{Postural Stability}

During each vibration condition an observer recorded any loss of stability that required the participants to grasp onto the support rail (Table 2). The results of these observations showed that losses of balance occurred primarily at the highest vibration magnitudes. The fore-and-aft posture caused substantially more cases of instability (68 grasps) compared to the lateral posture (22 grasps).

Table 2: Postural instability of subjects represented by number of grasps onto support rail at the highest vibration magnitudes*

\begin{tabular}{|c|c|c|}
\hline $\begin{array}{l}\text { Vibration Direction } \\
\text { (Axis) }\end{array}$ & Standing Posture & Total Number of Grasps \\
\hline \multirow[t]{2}{*}{ Fore-and-aft (X-Axis) } & Lateral & 6 \\
\hline & Fore-and-aft ** & 7 \\
\hline \multirow[t]{2}{*}{ Lateral (Y-Axis) } & Lateral ** & 4 \\
\hline & Fore-and-aft & 18 \\
\hline \multirow[t]{2}{*}{ Dual Axis (X-Y-Axes) } & Lateral & 12 \\
\hline & Fore-and-aft & 43 \\
\hline$*_{2.0 \mathrm{~ms}^{-2}}$ r.s.s. for single axis vibratio & $2.8 \mathrm{~ms}^{-2}$ r.s.s. for dual a & \\
\hline
\end{tabular}




\section{Discussion}

The results supported previous studies that have shown a progressive reduction in task performance with vibration (Lewis and Griffin, 1978). For both lateral and fore-andaft postures manual dexterity performance was reduced with each increase in vibration magnitude and the extent to which performance was affected increased with increasing vibration magnitude (Figure 2). Previous studies (Corbridge and Griffin, 1991; Griffin and Hayward, 1994 and Mansfield et al., 2007) have indicated that low levels of vibration may not adversely affect task performance. The results from the current study (Figure 2) offer a different perspective as reductions in task performance were found between the control condition and the lowest vibration condition $\left(0.5 \mathrm{~ms}^{-2}\right.$ r.m.s.). This could suggest that manual dexterity tasks are more sensitive to horizontal vibration than other tasks. An alternative explanation is that in this study the upper limb was not supported by the moving platform and was free to move, unlike earlier studies where there was some arm or hand support effectively grounding the contact point to the motion.

Subjective measures of task difficulty (Figure 3) showed a progressive increase in workload with an increase in vibration magnitude, supporting results found by Mansfield and Maeda (2005), where subjective ratings of intensity increased with vibration magnitude for both single axis and dual axis vibration conditions. Humans generally have the ability to compensate for adverse conditions and maintain a certain level of performance; however this usually results in an increased workload (Griffin, 1990). The results indicate that although the subjective workload increased, participants were not able to maintain manual dexterity performance as the vibration magnitude increased (Figure 2). This could suggest the requirements of the task 
exceeded the adaptation capabilities of the participants to cope with the adverse conditions (increased vibration magnitudes) or additional factors such as motivation, arousal and the importance of task may have contributed to the progressive reduction in performance.

Body posture has been identified by Harazin and Griffin (1998) as one of main factors affecting task performance during vibration exposure. Postural instability influences the surface contact with the vibration source, the position of the spine and can lead to increased muscular exertion in order to maintain balance (Mathews et al., 2006). Nawayseh and Griffin (2006) identified that loss of balance during horizontal vibration exposure was influenced by the base of support of the participant in the direction of movement. The base of support would be greatest and therefore provide increased stability when the standing posture is in alignment with the direction of movement. The greatest levels of stability occurred in a lateral posture for both x-axis and y-axis vibration. The fore-and-aft posture consistently showed greater instability irrespective of the direction of movement. Comments made by participants after completing of the testing session suggest that a staggered stance or combination of the two test postures would be the preferred posture for the majority of participants. Postural instability may have influenced the responses to vibration as the fore-and-aft posture persistently showed greater reductions in task performance and increased ratings of task difficulty than the lateral posture. Observations of stability also highlight the importance of grab rails and hand supports in environments where standing people are exposed to horizontal vibrations. In some environments awkward postures that reduce the ability to maintain balance might be unavoidable (such as crowded transportation). 
In the current study, exposure to vibration produced showed minimal postural effects. The fore-and-aft posture showed significantly $(p<0.05)$ higher decrements to performance than in the lateral posture at $2.8 \mathrm{~ms}^{-2}$ r.m.s. during dual axis vibration. Limitations such as the small sample size and possible learning effect within the task could explain the lack of significance at other vibration magnitudes. Subjective measures of task difficulty (Figure 3) were significantly $(p<0.05)$ higher in the foreand-aft posture compared to the lateral posture at magnitudes of 1.0 and $2.0 \mathrm{~ms}^{-2}$ r.m.s. during $\mathrm{y}$-axis vibration. These results suggest that at relatively low magnitudes of horizontal vibration $\left(<1.0 \mathrm{~ms}^{-2}\right.$ r.m.s.) some degree of activity interference will occur regardless of the standing posture and a comfortable posture for the individual should therefore be adopted. At higher magnitudes ( $>1.0 \mathrm{~ms}^{-2}$ r.m.s. $)$ the effects of standing posture on activity interference and task performance are more pronounced. Standing in a lateral posture (feet side-by-side) would provide better stability and potentially improved manual dexterity performance and reduced workload.

Although direct comparison between single and dual axis vibration could be misleading due to differences in the resultant vibration magnitudes, Figures 4 and 5 enable single-axis vibration and dual-axis vibration to be represented on a common magnitude scale. For y-axis vibration task performance was influenced to a lesser extent than for $\mathrm{x}$-axis vibration. It is important to note that these differences were only significant at a vibration magnitude $2.0 \mathrm{~ms}^{-2}$ r.m.s.. Griffin and Hayward (1994) showed that for seated participants at magnitudes of 1.0 and $1.25 \mathrm{~ms}^{-2}$ r.m.s., significant impairments in reading speeds occurred during both $\mathrm{x}$-axis and $\mathrm{y}$-axis vibration exposure. The discrepancy between these studies, regarding the magnitude 
at which the directional effects were observed could be explained by the differences in task characteristics. Reading tasks are influenced by vibration effects on visual performance whereas manual dexterity tasks would be influenced more by vibration that is transmitted to the upper body (the trunk, shoulders and hand). Nevertheless the results support the notion that task performance is higher during $y$-axis vibration than during $\mathrm{x}$-axis vibration.

The effects of multiple axis vibration have been found to be similar to the effect of single axis vibration corresponding to the root sum of squares (r.s.s) of the magnitudes in each axis (Lewis and Griffin, 1978). This method is commonly termed r.s.s. summation. By combining the single axis responses using this method, it was found that the task was clearly composed of two components, analogous to a Fitt's Law approach to performance. There was a constant portion, representing a minimum period for the completion of the task (observed during the control stimulus of the experiment under no vibration) and a variable portion that increased as a function of vibration.

Comparing the actual dual axis responses with the predicted dual axis responses, the percentage errors for time measurements and magnitude estimations were less than $8 \%$ and $11 \%$ respectively. This level of error in prediction would however be deemed acceptable and the r.s.s. summation method can therefore be used to estimate human responses to dual axis vibration based on single axis values. 
(a)

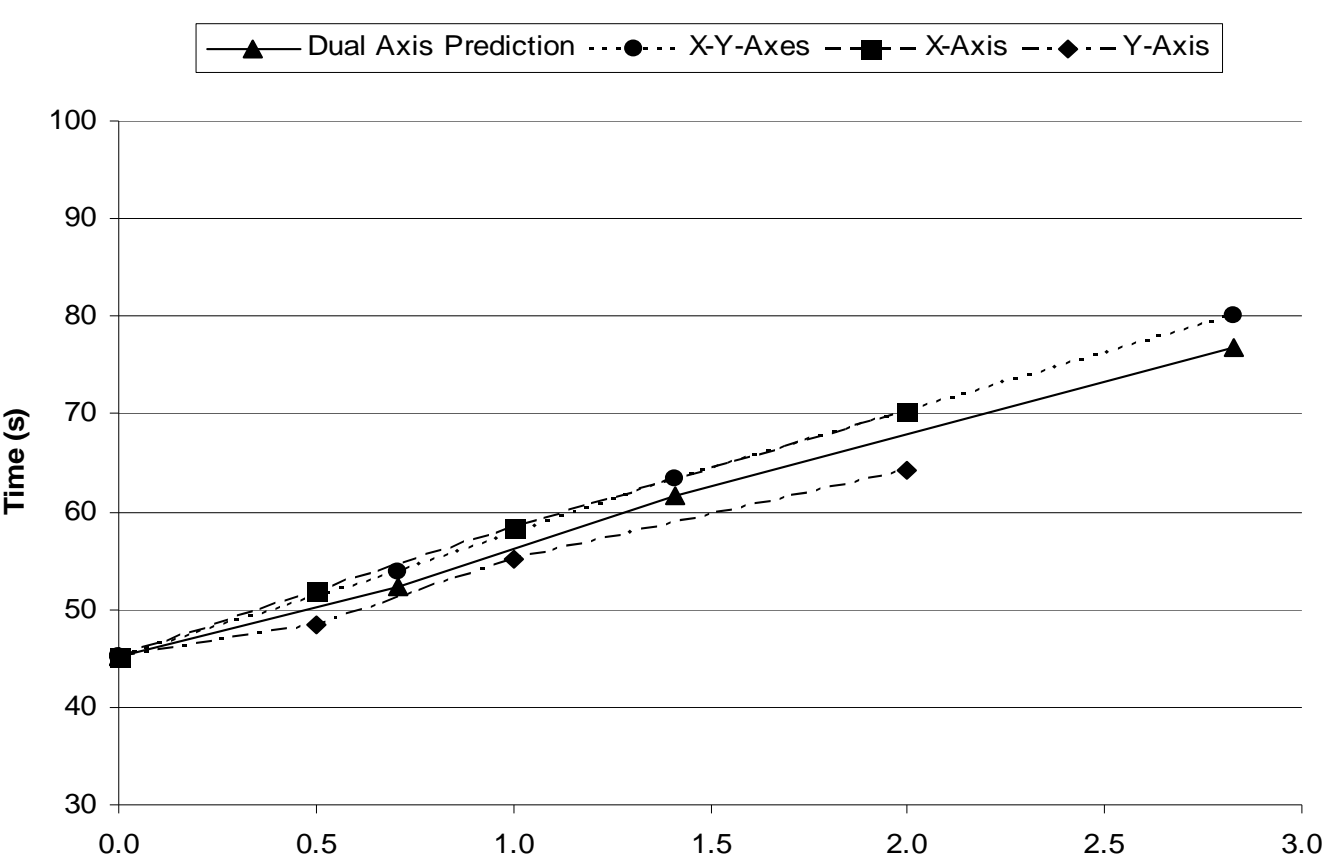

(b)

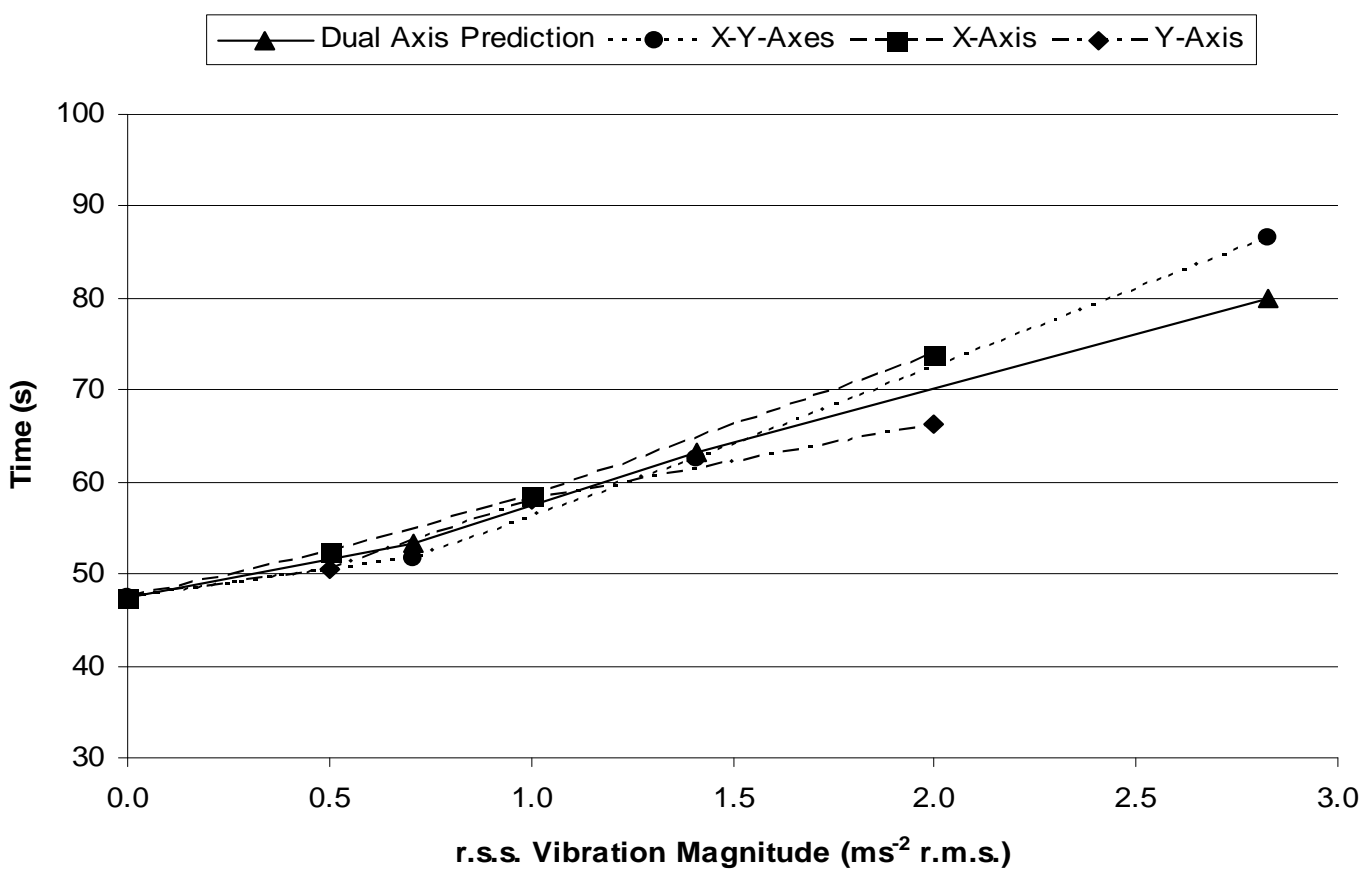

Figure 4: Comparison between horizontal vibration direction illustrating the mean time taken to complete the pegboard task for the (a) lateral posture and (b) fore-and-aft posture. 
(a)

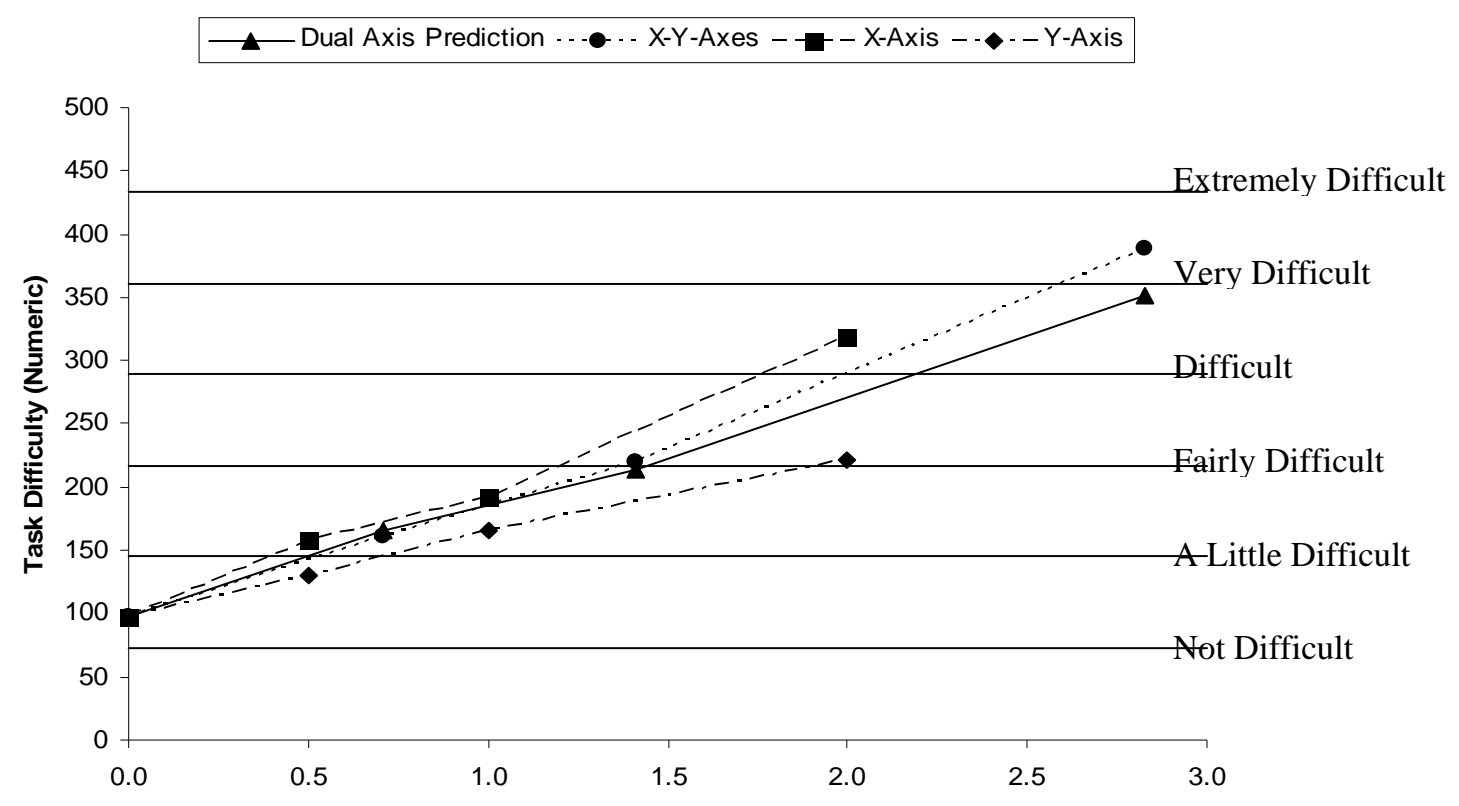

(b)

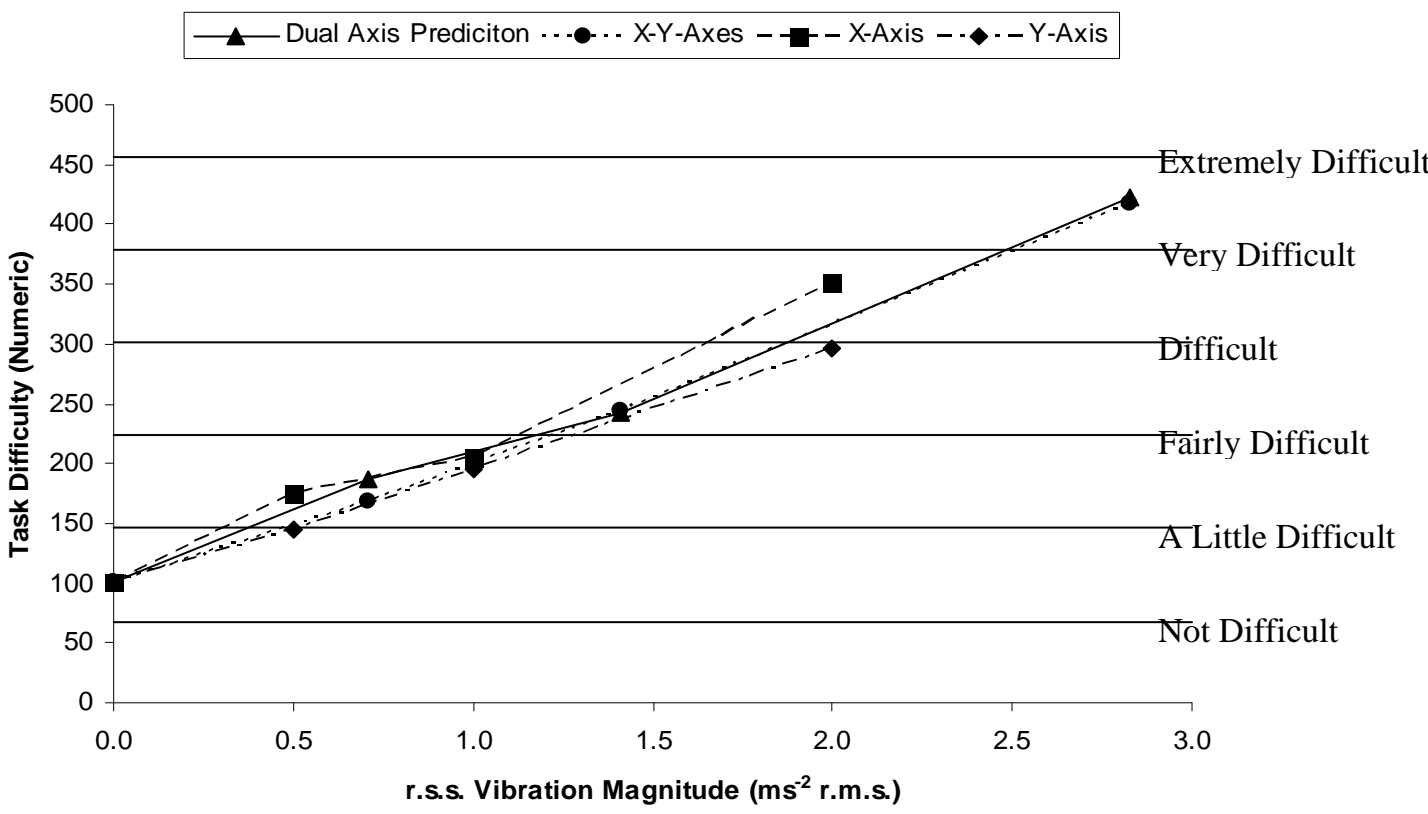

Figure 5: Comparison between horizontal vibration direction illustrating the task difficulty of the pegboard task for the (a) lateral posture and (b) fore-andaft posture. 
Considering subjective responses, the magnitude estimations and semantic ratings of task difficulty were combined so that numerical magnitudes could be obtained that related to the verbal descriptors associated with the semantic scale of difficulty. The calculated numeric magnitudes showed only marginal differences between lateral and fore-and-aft postures for each semantic descriptor.

The combined subjective responses (Figure 5) showed similar task difficulties for the $\mathrm{x}$ - and $\mathrm{y}$-axes and dual axis vibration. The $\mathrm{y}$-axis vibration produced slightly lower difficulty responses than x-axis vibration, with responses to dual axis vibration situated between those for single axis vibration. Based on these results, there appears to be no difference between task difficulty for single and dual axis horizontal vibrations. Comparison of task difficulty ratings at $2.0 \mathrm{~ms}^{-2}$ r.m.s. between the lateral and fore-and-aft postures indicated that perceived task difficulty for dual axis vibration exposure was largely unaffected by posture. Subjective responses obtained for dual axis vibration in the lateral posture (Figure 5(a)) corresponded to a 'Difficult' rating and only slightly above 'Difficult' in the fore-and-aft posture. Although the magnitude estimations of task difficulty increased between postures at this level of vibration, the semantic descriptors of difficulty (for example, 'Fairly Difficult' or 'Difficult') increased accordingly. The overall perception of task difficulty therefore remained relatively constant. The largest effect in subjective responses between postures was found for y-axis vibration, where responses that corresponded to a difficulty perception of 'Fairly Difficult' in the lateral posture increased to 'Difficult' in the fore-and-aft posture. Instability during y-axis vibration was higher in the foreand-aft posture than in the lateral posture and this could have influenced the perception of task difficulty. 
The small sample size and use of only one manual dexterity task mean the results from this study have limited applicability to the wide range of different tasks found in 'real-world' environments. The study does however, provide an insight into the response of standing individuals during vibration exposure that has previously been neglected. Future work should probably focus on determining performance using different types of tasks and additional standing postures.

\section{Conclusions}

1. Progressive reductions in task performance were found with increasing vibration magnitudes up to $2.0 \mathrm{~ms}^{-2}$ r.m.s. and $2.8 \mathrm{~ms}^{-2}$ r.m.s. for single axis and dual axis vibration respectively.

2. A slight postural trend showed the lateral posture provided greater stability than the fore-and-aft posture, however, the effects on performance in each axis were variable. Further investigation is recommended before conclusive postural effects can be identified.

3. The direction of movement showed that $\mathrm{x}$-axis vibration resulted in the greatest reductions in task performance, followed by dual axis vibration with y-axis vibration having the least effect on performance. By combining single axis responses using the r.s.s. summation method, dual axis responses may be estimated to within an $11 \%$ accuracy.

4. Based on subjective responses of task difficulty, the workload experienced by the participants increased progressively with increasing vibration magnitudes. 


\section{References}

Banister, P. A. and Smith, F. V. 1972, Vibration-induced white fingers and manipulative dexterity. British Journal of Industrial Medicine, 29: 264-267.

British Standards Institution. 1987, Measurement and evaluation of human exposure to whole-body mechanical vibration and repeated shock. BS6841.

Buckhout, R. 1964, Effects of whole-body vibration on human performance. Human Factors 6, 157-163.

Conway, G. E., Szalma, J. L. and Hancock, P. A. 2007, A quantitative meta-analytic examination of whole-body vibration effects on human performance. Ergonomics, 50(2): 228-248.

Corbridge, C. and Griffin, M. J. 1991, Effects of vibration on passenger activities: writing and drinking. Ergonomics, 34(10): 1313-1332.

Fraser, T. M., Hoover, G. N. and Ashe, W. J. 1961, Tracking performance during low frequency vibration. Aerospace Medicine 32, 829-835.

Griffin, M. J. 1990, Handbook of Human Vibration. London: Academic Press Limited. 
Griffin, M. J. and Hayward, R. A. 1994, Effects of horizontal whole-body vibration on reading. Applied Ergonomics, 25(3): 165-169.

Harazin, B. and Grzesik, J. 1998, The transmission of vertical whole-body vibration to the body segments of standing subjects. Journal of Sound and Vibration, 215(4): 775-787.

Lewis, C.H. and Griffin, M. J. 1978, A review of the effects of vibration on visual acuity and continuous manual control. II: continuous manual control. Journal of Sound and Vibration, 56(3): 415-457.

Malchaire, J., Rodriguez Diaz, L. S., Piette, A., Goncalves Amaral, F. and de Schaetzen, D. 1998, Neurological and functional effects of short-term exposure to hand-arm vibration. International Archives of Occupational Environmental Health, 71: 270-276.

Mansfield, N. J. 2005, Human Response to Vibration. London: CRC Press.

Mansfield, N. J. and Maeda, S. 2005, Comparison of subjective ratings of whole-body vibration for single- and multi-axis vibration. Presented at the $40^{\text {th }}$ United Kingdom Conference on Human Response to Vibration, Liverpool, England, 13-15 September.

Mansfield, N. J., Arora, Y. and Rimell, A. 2007, Computer use on moving trains: which pointing device? In P Bust (Ed) Contemporary Ergonomics, 255-260. 
Matthews, J. D., MacKinnon, S. N., Albert, W. J., Holmes, M. and Patterson, A. 2007, Effects of moving environments on the physical demands of heavy materials handling operators. International Journal of Industrial Ergonomics, 37: 43-50.

Nawayseh, N. A. and Griffin, M. J. 2006, Effect of frequency, magnitude and direction of translational oscillation on the postural stability of standing people. Journal of Sound and Vibration, 298: 725-754.

Newell, G. S. and Mansfield, N. J. 2008, Evaluation of reaction time performance and subjective workload during whole-body vibration exposure while seated in upright and twisted postures with and without armrests. International Journal of Industrial Ergonomics, 38: 499-508.

Paddan, G. S. and Griffin, M. J. 1993, The transmission of translational floor vibration to the heads of standing subjects. Journal of Sound and Vibration, 160(3): 503-521.

Pheasant, S. and Haslegrave, C. M. 2006, Bodyspace: anthropometry, ergonomics and the design of work. London: CRC Press.

Stevens, S. S. 1975, Psychophysics: introduction to its perceptual, neutral and social prospects. Wiley-Interscience. (see Mansfield and Maeda, 2005) 
Sundstrom, J. 2006, Difficulties to read and write under lateral vibration exposure: contextual studies of train passengers' ride comfort. KTH Doctoral Thesis, Stockholm, Sweden.

Tiffin, J. 1948, Purdue Pegboard Examiner Manual. Chicago, Illinois: Science Research Association Inc. 